\title{
Mirada y trompel'œal: La pregunta por la representación en Calderón
}

\author{
The gaze and trompel'œil: The question of representation \\ in Calderón
}

\author{
ValeRIA de LOS Ríos \\ Universidad Diego Portales. Santiago, Chile. \\ E-mail: vdelosrios@gmail.com
}

\section{RESUMEN}

Este texto analiza el problema de la mirada y la representación en el teatro deC alderón a partir de sus teorías pictóricas, sistematizadas en su horaciana "D eposición en favor de los profesores de la pintura". A través del examen de segmentos de sus obras, se configura el problema del engaño de los sentidos o trompel'oeil, propio de ese momento histórico. Al final del artículo se estudian específicamente las implicancias del mise-en-abime barroco, en el que el rey es el espectador ideal del espectáculo barroco, y a la vez es representado dentro del teatro.

Palabras claves: Calderón, Barroco, representación, trompel'œil.

\section{ABST RACT}

This text analyzes the problem of the gaze and of representation in the theatrical work of Calderón. It takes his theories, systematized in his $\mathrm{H}$ oracian "D eposition in favor of the teachers of painting", as a starting point. Through the examination of segments of his works, I configure the issue of the deceit of the senses or trompel'oeil, typical of this historical period. At the end of the article, I study specifically the implications of the baroque mise en-abime, in which the king is both, the ideal spectator of the baroque spectacle, and a character represented inside the work.

Keywords: Calderón, Baroque, representation, trompel'œil.

Recibido: 06-08-2007. Aceptado: 25-10-2007. 


\section{MIRAD A, REPRESENTACION Y TROMPE-L'CIL}

D

URANTE el Barroco ${ }^{1}$ la vista se había convertido en el sentido privilegiado, desplazando al oído - que mantuvo su hegemonía hasta el Renacimiento- a una posición secundaria (Amadei-Pulice, 1990). Los descubrimientos científicos ( $G$ alileo, Kepler) contribuyeron a una nueva concepción del espacio, y al nivel de la investigación científica, los supuestos imaginarios fueron reemplazados por la ciencia experimental que, en última instancia, es lo comprobable a través de los sentidos. Todo debía ser experimentado, pero como los sentidos engañan, éstos también fueron sometidos a duda². Según Foucault, en este periodo:

La época de lo semejante está en vías de cerrarse sobre sí misma. No deja, detrás desí, más quejuegos. Juegos cuyos poderes de encantamiento surgen de este nuevo parentesco entre la semejanza y la ilusión; por todas partes se dibujan las quimeras de la similitud, pero se sabe que son quimeras; es el tiempo privilegiado del trompe l'oal, de la ilusión cómica, del teatro que se desdobla y representa un teatro, del quid pro quo, de los sueños y de las visiones; es el tiempo de los sentidos engañosos; es el tiempo en que las metáforas, las comparaciones y las alegorías definen el espacio poético del lenguaje (1997: 58).

En esta época decambio, el problema de la representación y del ilusionismo óptico ocupan un lugar central. En su Foliedu voir ChristineBuci-G lucksmann (1986) se refiere a una "locura de ver" barroca que abarca a todas las artes y saberes de la época, y que se expresa en una insaciabilidad de la mirada. Segismundo en La vida es sueño es víctima de esta enfermedad crónica del siglo XVII, cristalizada metafóricamente en los "ojos hidrópicos" del príncipe?:

\footnotetext{
${ }^{1}$ En su estudio sobre la cultura del Barroco, José A ntonio M aravall (2000) define al Barroco como un periodo histórico producido por diversos factores, entre los que se cuenta la crisis económica, trastornos monetarios, guerras, el fortalecimiento de la propiedad agraria señorial y el empobrecimiento de las masas, que crean un sentimiento de amenaza e inestabilidad en la vida social y personal, dominada por las fuerzas represivas de la monarquía absoluta. Foucault (1997), por su parte, sitúa en el siglo XVII un cambio radical en el orden de los signos, es decir en la relación entre las palabras y las cosas: el signo tripartito del Renacimiento, basado en similitudes platónicas, es reemplazado por una relación binaria, que se definirá por el enlace de un significantey un significado. Pero esta unión tiene un carácter especial, ya no basado en la similitud. El pensamiento deja de moverse en términos de semejanza, poque es ésta justamentela que conduceal error. El Barroco es principalmente una época sin un punto de referencia unívoco, descentrada, dondeel único punto fijo posible es el punto de vista. La paradoja barroca pone a la vista como centro, siendo ésta múltiple, móvil y cambiante. Con esto, se abre paso a la pregunta clave sobre el estatus de la representación.

${ }^{2}$ Este es el movimiento cartesiano por excelencia.

${ }^{3}$ Todas las citas de obras de teatro de Calderón han sido tomadas de sus 0 bras completas ( $M$ adrid: Aguilar, 1969), indicándose el tomo y número de páginas al final de la cita.
} 


\begin{abstract}
Con cada vez que te veo nueva admiración me das, y cuando te miro más aun más mirarte deseo. O jos hidrópicos creo que mis ojos deben ser; pues cuando es muerte el beber, beben más, y de esta suerte, viendo que el ver me da muerte, Estoy muriendo por ver $(I, 503)$.
\end{abstract}

Visión, enfermedad y muerte están unidos en este pasaje. La visión como mirada suscita el deseo, pero como deseo no encuentra nunca su satisfacción. La mirada se identifica con el beber, que en el caso de la hidropesía, provoca la muerte. El deseo es la sed insaciable experimentada por Segismundo ante la visión de Rosaura. La única solución a la insoslayable disparidad entre el deseo y su realización es el exceso en la mirada, expresado en los versos "y cuando te miro más / aun más mirarte deseo". La visión actúa como el pharmakon derrideano (1975): es a la vez medicina y veneno.

El desarrollo dela pintura contribuyó en gran medida a la expansión deeste furor visual, puesto que es la principal responsable de la proliferación deimágenes, planos espaciales y perspectivas durante el Barroco. En la época de Calderón, la pintura como disciplina ocupaba una posición marginal en comparación al lugar que ostentaba en Italia o en los Países Bajos. Pero por ese entonces, en España ya empezaban a desplegarse argumentos para que el arte pictórico fuera considerado dentro delas llamadas "artes liberal es"4. Es precisamente a través de Calderón que recibimos una de las más interesantes defensas de la pintura. El 8 de julio de 1677, el poeta firmó una declaración jurídica que conocemos con el nombre de "D eposición en favor de los profesores de la pintura en el pleito con el procurador general de esta villa, sobre pretender éste se les hiciese repartimiento de soldados" (1969). En ella, el autor reconoce haber tenido siempre una natural inclinación por la pintura, llegando incluso a considerarla el artede las artes, que "a todas domina sirvién dose de todas" (211). Calderón, contagiado de esta locura de ver, describe en qué medida la pintura contiene a todas las demás artes, Ilamando especial atención la comparación que hace de ésta con la retórica, por los ecos horacianos de su doctrina: "pues Retórica muda, no persuaden menos que pintadas sus voces, articulados sus matices ¿qué mayor elo-

\footnotetext{
${ }^{4}$ Las "artes liberales" en la época de Calderón eran la Gramática, la D ialéctica, la Retórica, la Aritmética, la M úsica, la G eometría y la Astronomía.
} 
cuencia que la que representa?" (212). En la comedia Bien vengas, mal, si vienes solo encontramos alusiones a esta estrecha relación entre escritura y pintura:

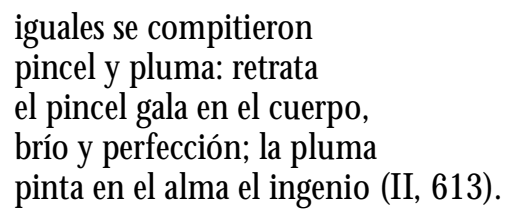

Pluma y pincel encarnan al arteliterario y al pictórico respectivamente, siendo la pintura la encargada de retratar físicamente y con perfección, mientras quela poesía seencarga metafóricamente de "pintar" o inscribir una abstracción - el ingenio- en el alma. Tanto para Calderón como para Horacio (1971), la pintura es el modelo ideal de la poesía (ut pictura poesis erit), porque aquélla es capaz de persuadir, mover y deleitar mejor que cual quier otra disciplina artística. Para Calderón, la poesía debe ser una pintura que habla, mientras que la pintura debe comportarse como una poesía muda.

El modelo pictórico trae consigo la pregunta sobre la relación entreel modelo y la copia; entre la realidad y la apariencia; entre lo representado y la representación. El problema barroco por excelencia es el de la imposibilidad de distinguir entre uno y otro, es decir, el problema del engaño visual o trompel'œil. Campaspe en la obra de Calderón D arlo todo y no dar nada experimenta la visión de su retrato como la experiencia de haber sido reflejada en un cristal:

¿Q ué es lo que miro! ¿Es por dicha
lienzo o cristal transparente
el que me pones por delante?
Q ue mi semblante me ofrece
tan vivo, que aun en estar
mudo también me parece;
pues al mirarle, la voz
en el labio se suspende
tanto, que aun el corazón
no sabe cómo la aliente.
¿Soy yo aquélla, o soy yo, yo? (I, 1050).

La visión es tan poderosa, que puede llegar a producir duda sobre la propia existencia. Campaspe duda de si lo que ve es un cuadro o un espejo. El retrato funciona como duplicación del sujeto retratado, y la semejanza es tal, que sólo el movimiento o la ausencia de éste revela el engaño. Este "estadio del espejo" barroco es previo a laintervención del cogito cartesiano. Encontramos otro ejem- 
plo de esto en la jornada tercera de La sibila de oriente, donde se produce una conversación entre I rene, Sabá y Salomón, que ilustra la reflexión de Calderón respecto a este tema. El problema radical que Irene le plantea a Salomón es el siguiente: ¿se puedeimitar al C reador? ¿Q uépasa si la perfección dela imitación es tal, que incluso engaña al espectador que es incapaz de percibir el artificio? El rey Salomón deberá distinguir entre una rosa pintada y una real, y la respuesta decidirá - ante los ojos de Sabá- la sabiduría del rey. Salomón ha sido expuesto a un trompe|'œil y deberá decidir qué es realidad y qué apariencia:

\author{
IRENE. - ¿Podrá el monarca mayor, \\ con poder o con ingenio, \\ criar, Señor, una rosa? \\ SALO M - - No; que el clavel más pequeño \\ del pincel de $D$ ios es rasgo \\ y no hay poder en el suelo \\ que crear una flor pueda, \\ porque este nombre supremo \\ de criar, es de Criador, \\ no de criatura (I, 1175).
}

La escena está ambientada en un jardín, elemento elocuente si pensamos en queel diálogo mismo sebasa en una discusión sobre la relación entre el arte y la naturaleza: el jardín constituye un espacio heterotópico en que naturaleza y artificio se confunden 5 . En la "D eposición... " Calderón (1969) expone la doctrina del D euspictor, rescatada de autores clásicos como Empédocles y Píndaro, que describen a Dios como artista, tal como lo expresa el personaje deSalomón en el texto citado. La C reación es representada metafóricamente como el trabajo de un Dios-pintor cuyo resultado final - la obra- es el universo mismo. La condición del Dios-pintor trasciende de la creación de mundo, puesto queCalderón afirma en su "D eposición..." que Dios se autorretrató en el cendal de Verónica, en la Sábana Santa, en el Santo Sudario y, por supuesto, en el hombre mismo, "pues le sacó del ejemplar de su idea, imagen y semejanza" (219). De este modo, para Calderón el pintor o el literato-pintor es un jugador de la técnica divina: "con un pincel, es segundo / autor de la natural eza" (II , 429). I reneen La sibila de oriente es la defensora de esta doctrina pictórica:

\footnotetext{
${ }^{5}$ JoséVericat ha señalado: “La teatralidad del jardín vienepues a reflejar no sólo laforma ilusoria de lo natural, sino lo natural de la ilusión, como las dos caras, el anverso y el reverso, de una sola ontología de la realidad" (1993: 111).
} 


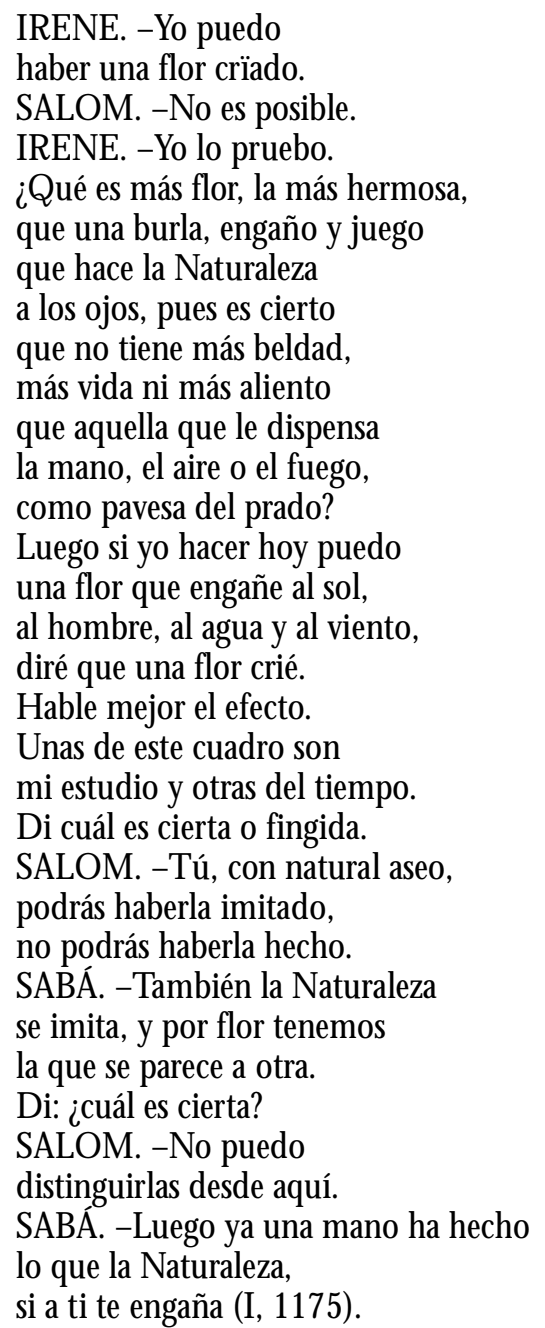

El problema de la representación reside, entonces, no tanto en la creación ni en la imitación en sí -el pintor es un creador en segundo orden-, sino que en la posibilidad de engaño. La vista es el sentido privilegiado durante el Barroco, pero esto no significa que no exista una profunda desconfianza en ella. El problema de discernimiento entre la realidad y la apariencia, del ilusionismo 0 trompel'œel, es producto de la utilización de la perspectiva, y el éxito de esta técnica consiste en que el observador tome lo pintado como real, es decir, que la representación se haga pasar por el referente. El problema del engaño barroco es, por tanto, principalmente óptico. La solución al engaño surgirá dentro de ese mismo paradigma: 


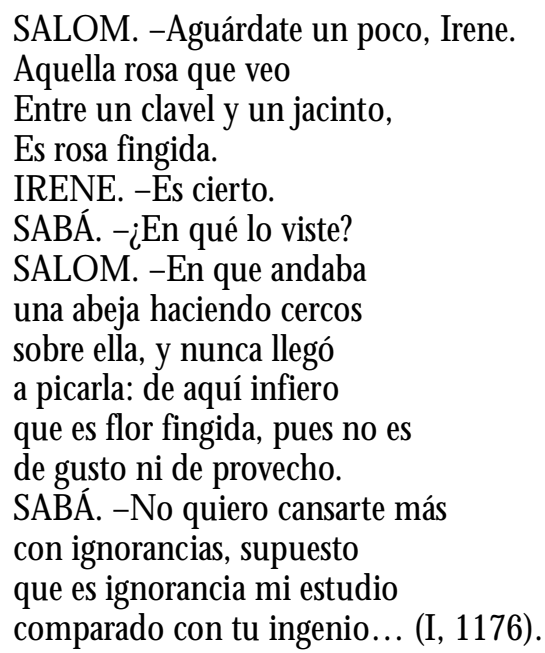

El ingenio se presenta aquí como la facultad privilegiada. Este consiste en una agudeza visual, no en una negación dela visión. El ingenio implica mirar de cierta manera, que permita descifrar entre lo aparente y lo real. Es, quizás, la mirada oblicua que exige la representación pictórica conocida como anamorfosi $\varsigma^{6}$. En Barroco Severo Sarduy (1999) se refiere a la "lectura marginal" de la anamorfosis, que permite al sujeto acceder a un segundo sentido. Esta aseveración supone la existencia de un reverso en cada representación, que sólo será revelado medianteel desplazamiento oportuno del observador. En La simulación - también del autor cubano (1999)- hay una referencia explícita al "lector de anamorfosis", al que Sarduy relaciona con el analista en la práctica psicoanalítica'. La lectura barroca de la anamorfosis - que aquí comparamos con el ingenio barroco- se produciría mediante dos movimientos contiguos: el primero, una asimilación delo visto a lo real; y el segundo, un alejamiento y especificación del objeto, que

\footnotetext{
${ }^{6}$ El estudioso dela anamorfosis Jurgis Baltrusaitis afirma queéstetipo de representación: “Instead of reducing forms to their visible limits, it projects them outside themselves and distorts them so what when viewed from a certain point they return to normal" (1977: I). Galileo describe a la anamorfosis del siguiente modo: "Esas pinturas que consideradas de lado y desde un punto de vista determinado, nos muestran una figura humana, pero están construidas siguiendo una regla de perpectiva tal que, vistas de frente, como se hace natural y comúnmente con las otras pinturas, no dan a ver más que una mezcla confusa y sin orden de líneas y de colores, donde con mucha aplicación se puede formar la imagen de ríos y de caminos sinuosos, de playas desiertas, de nubes y de extrañas quimeras" (Sarduy, 1999: 1219).

${ }^{7}$ Sarduy cita los Écrits de Jacques Lacan para confirmar esa anal ogía: "Su acción terapéutica, al contrario, debe ser definida esencialmente como un doble movimiento gracias al cual la imagen, al comienzo difusa y rota, es regresivamente asimilada a lo real, para ser progresivamente desasimilada de lo real, es decir, restaurada en su realidad propia" (1999: 1275).
} 
conlleva una crítica de lo figurado y una desasimilación de lo real. Este último es el gesto del ingenio barroco por excelencia.

La problemática de la representación visual secomplejizó aun más cuando el teatro desarrolló - a partir de la pintura- la escenografía perspectivista, traída desdel talia durante el siglo XVII ${ }^{8}$. EI dramaturgo comenzó a imitar la naturaleza con las habilidades del pintor. El espacio escenográfico comenzó a percibirse de otro modo, puesto que la perspectiva escénica representa - 0 aparenta representar- en las mismas dimensiones de la vida. En consecuencia, se evolucionó desdela simplicidad de la antigua escena clásica arquitectónica, con sus pórticos y columnas, hasta la escenografía pictórica italiana, con paneles pintados en perspectiva: la escena se empezó a percibir por primera vez como tridimensional, cóncava y mutable, con un eje central de orientación, la prospettiva di mezzo (Amadei-Pulice, 1990). La escena teatral tomó la forma de un tabelaux vivant, técnica comúnmenteutilizada por los pintores de la época para real izar sus obras. El teatro se convirtió en una pintura viva, y con ello surgió el tópico - que encontramos insistentemente en Calderón- del mundo como teatro, que se relaciona metonímicamente con el de la vida como sueño. En su estudio sobre Calderón y el Barroco, Amadei-Pulice afirma:

El lugar escénico barroco es ficticio y apariencial, pero verídico a los ojos. El engaño de la vista que crea la visión prospéctica, duplicando los lugares del mundo real, hace posible la sustitución necesaria, la representación de uno por otro, que le dará al teatro barroco su base epistemológica como el teatro representativo del "gran teatro del mundo" (1990: 113-114).

\section{POLITICA Y REPRESENTACION : EL CUERPO DEL REY}

En 1635, inmediatamente después de la muerte de Lope de Vega, C al derón fue nombrado dramaturgo de la corte. Cinco años antes, en 1630, el conde duque de O livares había iniciado la construcción de un nuevo palacio en el cual celebrar fiestas que mitigaran la melancolía del rey y que potenciaran la gloria de España en Europa, a pesar de que por aquella época la decadencia económica, política y militar ya mostraba sus primeros síntomas. El Palacio del Buen Retiro fue inaugurado en 1633, pero el Coliseo del Buen Retiro - el teatro en sí- sólo

\footnotetext{
${ }^{8}$ Alrededor de 1630 el italiano Cosimo Lotti diseñó el Coliseo del Buen Retiro, que sigue el prototipo del teatro Farnese de Parma, con una escena única, un punto de vista central y bastidores lateral es corredizos. Antes que él, Gulio Fontana ya había traído a la corte madrileña maquinarias similares, pero habían sido montadas, a fal ta deteatro, en escenarios portátiles al aire libre(AmadeiPulice, 1990).
} 
estuvo terminado en 1640. Cosimo Lotti diseñó el teatro a la manera italiana, reservando para el rey un sitial privilegiado: no debía estar ni en un lugar muy alto ni en uno muy bajo, sino más bien en un sitial elevado, desde donde se pudiera observar sin distorsión. Esta es la perspectiva real, que se ubica en el extremo opuesto de la prospectiva di mezzo, perspectiva artificial o aparencial y cóncava de la escena, que converge hacia el foro. Los reyes son el sujeto privilegiado de la mirada, pero son, a la vez, el objeto de ella. M elveena $M$ ack endrick afirma que durante el Barroco la figura del rey se ha convertido en un espectáculo en sí:

This spectacle included the royals as well as the play. Thearrival and departure of the King and his family on these court occasions were conducted with the utmost ceremony and the extremely formal behaviour of the monarch throughout was that of a man who knew that he was the centre of the theatre of court life (1989: 222).

Las apariencias de la escena, el trompel'œil y la dialéctica de las miradas siempre convergen hacia el punto de vista del rey. Pero si la performance teatral cortesana tiene como "espectador ideal" al rey9", ¿qué sucede, por ejemplo, con representaciones teatrales en que el rey no sólo es el público a quien se dirige la obra, sino cuando él mismo es representado como personaje dentro de ella? Si el rey es a la vez espectador y espectáculo, estamos ante un juego de espejos. La duplicación del cuerpo del rey tiene connotaciones no sólo estéticas, sino que también políticas. Ernst Kantorowicz (1957) ha postulado la doctrina de los dos cuerpos del rey, en que uno de ellos es natural y mortal, y el otro inmaterial y político, capaz de garantizar la soberanía y la estabilidad política. La acción ocurrida al cuerpo duplicado del rey se traspasa al peso simbólico que éste tiene. En D arlo todo y no dar nada de Cal derón, encontramos un argumento dramático que trata justamente de la problemática de la representación real: la obra utiliza como en otras de la época la estructura de la puesta en abismo (de la obra dentro de la obra). Pero no se trata en este caso del teatro dentro del teatro, sino dela pintura dentro del teatro. El rey Alejandro quiere ser retratado para enviarle su imagen a su prometida, que así lo exige. El único obstáculo es que su prometida no lo conoce y él tiene un defecto físico en el rostro. Alejandro tendrá que elegir entre la propuesta de tres eximios pintores: Timantes, Zeuxis y Apeles:

\footnotetext{
${ }_{9}^{9}$ Según Diane Fox el lugar del rey es esencial en el Barroco español: "In Spain as elsewhere in Europe, themonarch had becomethemost visibleand at thesametimethemost intriguing personality in the community... the king was essentially an actor, directed on the stage of national attention by complex rules of protocol and public expectations" (1986: 2).
} 
TIM . - H uélgome que sea el primero, porque habiendo visto esotros no hiciérades de este aprecio. [D ale un retrato.]

ALEJ. - Este no es retrato mío.

TIM - ¿ ¿Cómo?

ALEJ. - Como en él no veo

Esta mancha, que borrón es de mi rostro, poniendo en disimularla todo su primor el pincel vuestro lisonjero habéis andado en no decírmela, siendo casi traición que en mi cara me mintáis. Infame ejemplo da ese retrato a que nadie diga a su Rey sus defectos; pues ¿cómo podrá enmendarlos, si nunca llega a saberlos? Tomad, tomad el retrato, Castigado el desacierto [Rómpele.] de la lisonja: con que perezca por lisonjero $(I, 1027)$.

En el cuadro de Timantes el defecto del rey ha sido obliterado, pero esta estrategia, en lugar de surtir un efecto adulatorio, lo condena. El argumento esgrimido por el rey para su desprecio de esta obra, es la falsedad y el silenciamiento de sus fallas. El monarca busca en la representación la posibilidad de ver sus errores, para luego enmendarlos. Al igual que en la doctrina horaciana, la pintura - como la poesía- debe no sólo deleitar, sino que también y principalmente, educar. El segundo pintor, Zeuxis, aplica la estrategia opuesta:

ZEUX. - [Aparte.]

Por lo menos,

Yo en él no le callo nada.

[D ale un retrato.]

ALEJ. - M ás parecido está el vuestro;

Pero no menos culpado.

ZEUX. - ¿En qué, señor?

ALEJ. - En que viendo

estoy mi defecto en él

tan afectado, que pienso

que en decírmele no más

todo el estudio habéis puesto: 


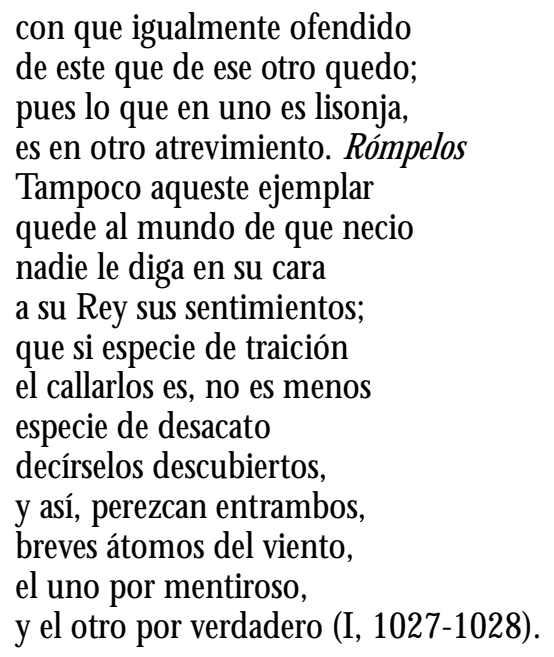

En este parlamento, Alejandro critica también la versión artística que expone los defectos del rey ante sus propios ojos sin recato al guno. Al parecer, ni la creación artística idealista - que corrige los defectos del rey, haciéndolo parecer lo que no es- ni la realista o naturalista - que refleja sus defectos con meticulosidad- son la alternativa correcta. Tanto las representaciones falaces como las verdaderas son destruidas y lanzadas al viento. ¿Q ué posibilidad de representación queda, entonces? Veamos el caso de Apeles:

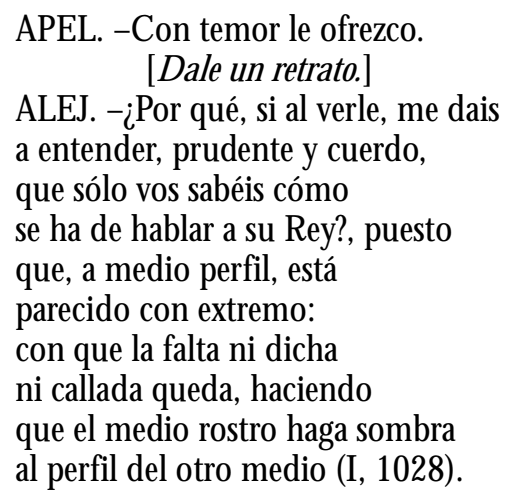

La solución intermedia es no desplegar un lienzo con los defectos, pero tampoco ocultarlos. Apeles es prudente 0 ha tenido el ingenio suficiente para no caer en ninguno de los dos extremos antes mencionados. La creación de Apeles juega en el campo de la política, puesto que dice sin decir, utiliza recursosquele permiten dar cuenta de los defectos sin exponerlos de manera explícita. En tér- 
minos de estrategia retórica, la pintura de A peles implica una perspectiva específica - el perfil del modelo- y el claroscuro: el perfil "sano" oscurece al enfermo, sin ocultarlo completamente. Alejandro agrega al final de su alabanza a A peles:

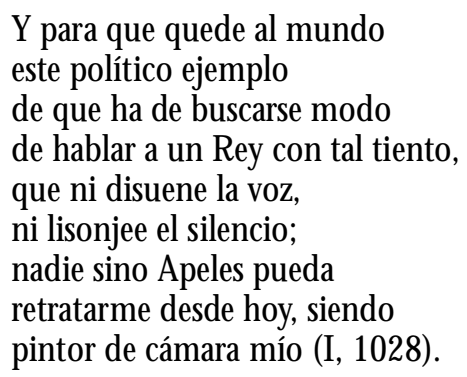

El problema de "lo histórico" está en la base de la preocupación real por la representación. En la obra de Calderón, el rey Alejandro destruye los retratos hechos por Timantes y Zeuxis porque no quiere dejar evidencia de la infamia a la posteridad. La importancia de la representación está en que ésta se ha convertido en la historia misma. La estructura en abismo de D arlo todo y no dar nada permite también leer el gesto pictórico de A peles como el propio gesto calderoniano como dramaturgo de la corte ${ }^{10}$. En la segunda jornada de la primera comedia conocida de Calderón, Amor, honor y poder, el rey Eduardo se esconde en el jardín de palacio para poder abordar a Estela. EI hermano deEstela, Enrico, la sorprende en una situación comprometedora, que amenaza el honor de la joven. Ella disimula y el rey se hace pasar por su propio retrato. Al encontrar a Estela en el jardín, Enrico le dice:

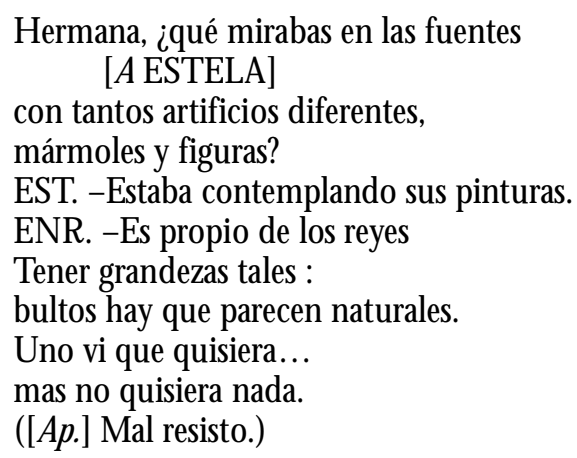

${ }^{10}$ En este punto es interesante notar que en la obra mencionada, Apeles es premiado por el rey, quien llega incluso a cederle a Campaspe, de quien ambos están enamorados. 
Yo pienso, hermana, que el mejor no has visto :

Llega y verásle.

EST. - [Aparte. ]

¡Ay cielos! El se atreve

a descubrir al Rey, y él no se mueve (II, 79).

En este fragmento vemos en escena la estrategia de ocultamiento del rey. Cuando es descubierto, sehace pasar por una apariencia, por un lienzo. Enrico, sabiendo que se trata de un engaño, entra en el juego alabando la excelente imitación del monarca, reconociendo que al verla no puede resistir el impulso de arrodillarse ante ella:

EN R. - Este es del R ey tan natural retrato,
que siempre que su imagen considero,
llego a verle quitándome el sombrero,
con la rodilla en tierra: [así le acato].
Y si el Rey me ofendiera
de suerte que en la honra me tocara,
viniera a este retrato y me quejara,
y entonces le dijera
que tan cristianos reyes
no han de romper el límite a las leyes;
que mirase que tiene sus Estados
quizá por mis mayores conservados,
con su sangre adquiridos,
tan bien ganados como defendidos (II, 79).

El ingenio de Enrico radica en que, aprovechando el contexto aparente, dice que si el rey afrentara su honor - que es el caso, porque su hermana soltera ha sido encontrada en una situación comprometedora- él se quejaría frente a su retrato. M ás aun, Enrico le recuerda al rey, casi en tono filosófico y recordando algunas teorías políticas de la época ${ }^{11}$, que su poder proviene de sus vasallos. Enrico, apelando más al cuerpo político de rey que al natural, simula estar frente a una representación, sabiendo que está frente al rey mismo. Tal como sucede en La vida es sueño, la estructura monárquica no es cuestionada en sí - el respeto a la figura real es evidente y finalmente, como en todas las obras de C alderón, el rey recapacita y enmienda sus errores-, pero de todos modos es posible encontrar una crítica a ciertas prácticas de la monarquía absoluta, y un afán de educar no sólo al pueblo, sino que también al monarca que lo gobierna. El mismo Calderón.

${ }^{11}$ Para mayor información sobre las teorías políticas en la época de Calderón, ver Fox: Kings in 
tópico barroco de la "vida como sueño" - producido entre otros factores por el engaño de los sentidos y el trompe l'œil pictórico o teatral- sugiere didácticamente quetanto el rol del súbdito como el del rey pueden ser meras fantasías, pero que aun así, es necesario actuar de modo ético.

\section{CONCLUSION}

En este texto se ha analizado la producción de Calderón de la Barca dentro del paradigma Barroco. Respecto a este periodo histórico, se ha estudiado la preponderancia de la visión como sentido privilegiado, que pone al tema de la representación en un lugar central. La obra teatral de Calderón problematiza la idea de representación, tanto en forma de trompe l'œil, como en relación a la representación del rey, quien como figura central de la monarquía absoluta se ha convertido en un espectáculo en sí mismo. Si bien en La vida es sueño Segismundo es víctima de la "locura de ver" barroca, en la que la mirada se presenta como un deseo insaciable, en Darlo todo y no dar nada y La sibila de oriente se desconfía de la visión como un sentido engañoso. En $D$ arlo todo y no dar nada el rey se preocupa de su autorrepresentación para no engañar ni tampoco presentar una visión indigna de sí mismo, mientras que en Amor, honor y poder simula ser una representación. Al convertirse en un objeto, el rey es contemplado y se lo interpela "como si" se tratase de él mismo en persona. En este caso, el ingenio del súbdito Enrico permite decir sin decir, pasar un mensaje crítico al monarca de manera diplomática y prudente. Así, el ingenio se presenta para el Barroco como una facultad excepcional, que permite distinguir el engaño de lo real -como el rey Salomón en La sibila de oriente- y a veces, incluso desafiar a un nivel simbólico el poder absoluto del rey.

\section{REFERENCIAS}

Amadei-Pulice, M aría Alicia. 1990. Calderón y el Barroco. Exaltación y engaño de los sentidos. Amsterdam-Philadelphia: John Benjamin Publishing Company.

Baltrusaitis, Jurgis. 1977. Anamorphic Art. N ew York: H arry N . Abrams, Inc. Publishers. Buci-Glucksmann, Christine. 1986. La folie du voir. Paris: Éditions Galilée.

Calderón de la Barca, Pedro. 1969. O brascompletas. Tomo I. D ramas, Edición, prólogo y notas de Angel Valbuena Briones. M adrid: Aguilar.

- . 1960. O brascompletas. Tomo II.Comedias. Edición, prólogo y notas de Ángel Valbuena Briones. M adrid: Aguilar.

- 1969. “D eposición de D. Pedro Calderón de la Barca en favor de los profesores de la pintura, en el pleito con el procurador general de esta corte, 
sobre pretender éste se le hiciese repartimiento de soldados". El pintor de su deshonra. Ed. M anuel Ruiz Lagos. M adrid: Ediciones Alcalá, pp. 209-219.

D errida, Jacques. 1975. La diseminación. M adrid: Editorial Fundamentos.

Foucault, M ichel. 1997. Las palabras y las cosas. M éxico y España: Siglo Veintiuno Editores.

Fox, Diane. 1986. Kings in Calderón. London: Tamesis Books Limited, 1986.

H oracio. 1971. "Art of Poetry". Critical theory since Plato. Ed. H azard Adams. N ew York, Chicago, San Francisco, Atlanta: H arcourt Brace Jovan ovich, Inc., pp. 68-75.

Kantorowicz, Ernst. 1957. TheKing'sTwo bodies: A study in medieval political theology. Princeton: Princeton UP.

M acK endrick, M elveena. 1989. Theatre in Spain 1490-1700. Cambridge, N ew York, Australia: C ambridge UP.

M aravall, José Antonio. 2000. La cultura del barroco. Barcelona: Ariel.

Sarduy, Severo. 1999. O bra Completa. España: G alaxia G utemberg Círculo de Lectores.

Vericat, José. 1993. "Barroco como paradigma”. Barroco y neobarroco. M adrid: C írculo de Bellas Artes V isor dis, pp. 101-113. 
